\title{
Studying Changes in Physical and Mechanical Properties of Polyethylene Pipes in Bending
}

\author{
Daniil Serebrennikov ${ }^{1, *}$, Vladimi Berg ${ }^{1}$, Vadim Ivanov $^{1}$, and Natalia Silnitskaya ${ }^{1}$ \\ ${ }^{1}$ Industrial University of Tyumen, 625001 Volodarskogo str. 38, Tyumen, Russia
}

\begin{abstract}
In recent years, polyethylene pipes are used more and more often in the gas industry. In the construction of pipeline, especially for trenchless laying and repairing, they are subject to considerable bending stresses. The magnitude of the stress in the pipe wall can briefly approach the yield point. The article is devoted to the study of mechanical characteristics of polyethylene pipes at short bending. The results can be used for engineering calculations at trenchless laying and repairing of pipelines.
\end{abstract}

\section{Introduction}

It is known that the peak of the construction of trunk pipelines in the Russian Federation took place in 60-80th years of the last century and today most of them are in need of overhaul including replacement of pipes $[1-9,10,11]$. If we consider the pipeline repair in terms of manufacturing operations, it is as well as the laying includes:

- delivery of pipes manufacturers on pipe-welding bases;

- welding of individual tubes into stalks;

- development of the trench;

- welding a string whip into of the pipeline;

- laying into the trench;

- backfilling of the trench.

It should be noted that in the construction and repair of pipelines, most of the economic and labor costs (about 75\%) are spent on earthworks. Therefore more attention is paid to trenchless pipeline repair methods recently that reduce the amount of required process operations including excavation, and hence increase the repair speed and reduce the cost $[7$, $8,15]$. Patent search $[1,2]$ conducted by the author showed that there is a growth of inventions, related to trenchless pipeline renovation in recent years. Published patents are directed both to modernization of existing units and aggregates of equipment for trenchless laying and repair, and to implementation of new methods. Patented methods are different on the principle of implementation, but all of them can be divided into several areas, namely:

- pulling existing pipeline into the adhesive shells;

\footnotetext{
* Corresponding author: $\underline{\text { daniilsereb } @ \text { yandex.ru }}$
} 
- destruction of the old pipe and laying the new one in its place;

- protective coating of the inner surface of the pipeline;

- pulling the polymer pipe inside an existing metal pipe.

It is known that polymer materials are the most promising ones today because of the diversity and uniqueness of their properties, as well as the universality of their obtaining. This is due to the fact that except for the polymers, fillers, stabilizers, reinforcement and other additives, are widely used in their structure, through which the materials obtained can be used in almost all industries. The polymers can even exceed the commonly used materials such as metals by many properties due to lower specific weight, high corrosion resistance and thermal insulation properties, low manufacturing costs, etc. [1-24]

Based on the abovementioned, it can be argued that the method of pipeline carrying capacity recovery with the use of polymeric inserts is quite promising. As a consequence, in the development of such methods, it should be considered that during the repair work, polymer pipe may be subjected to a short-term bending on a large enough angle, and have considerable stretching influence on the traction at installation. Because of this, it is necessary to know if its strength characteristics are remaining [2, 3, 4].

\section{Experimental part}

To study the behavior of polyethylene pipe in bending, an experimental unit was made. The unit (Figure1) looks like a frame made of U-sections. In the framework guides of different radii are set. Fixing of the pipes was carried out with the quick-detachable support, which is attached to the frame. The bended surface of guides performed with radii, size of which is within the range of possible use under real conditions $[6,7]$. Choosing bending radii guides is justified as follows. According to the requirements to ensure defined physical and mechanical properties at transportation and storage, polyethylene pipes must be wound on the bay with a diameter of at least 20 diameters of the pipe itself. Considering that that the thrust transmitting power from the traverse on investigated samples of pipes can endure a limited load, experiments were carried out with the pipes with a diameter up to $40 \mathrm{~mm} \mathrm{[5}$, 6]. The task of the study was to consider the possibility of single short pipe bend radius at less than what is presented above requirements while maintaining the strength of the pipe characteristics. Based on these conditions, the brackets radii were carried out as follows: 80 $\mathrm{mm}, 157.5 \mathrm{~mm}$ and $315 \mathrm{~mm}$ because these values are less than the radius at which providing the strength characteristics is guaranteed. Fig. 1.

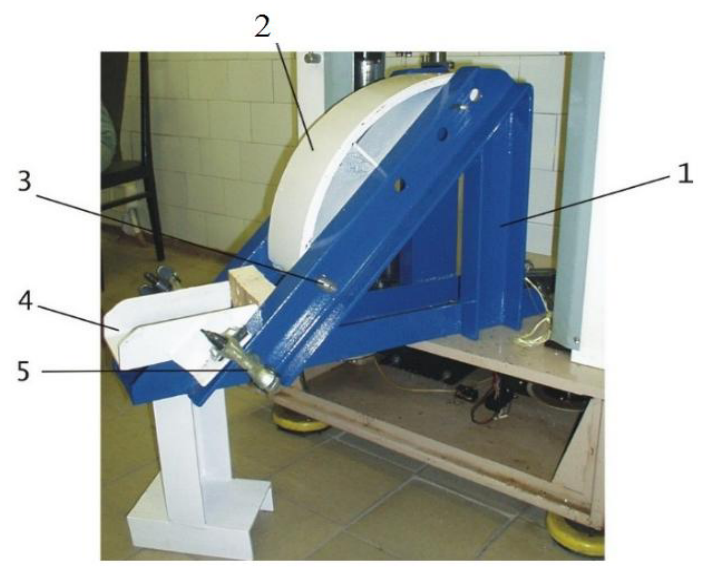

Fig. 1. Device for testing polyethylene pipes bending.; 1 - frame, 2 - guide; 3 - bolt joint; 4 - quickdetachable support; 5 - clamp. 
For the static tests on the deformation of pipe under bending, the sample was placed on the bracket and was fixed at one end. To the other end of the tube thrust was attached, in its turn, connected to the movable beam and dynamometer. During the experiment, a sample of the pipe was pressed to a bracket all over its bending surface. After a dense pressing, a mechanism switched off, measurements of changing the diameter of pipe samples at intervals of $0,2,5$ and 10 min were carried out. (Fig. 2)
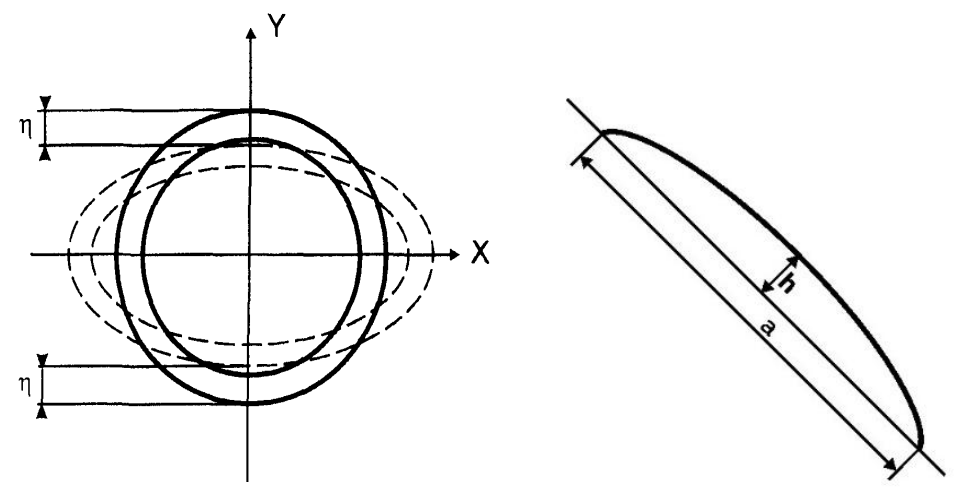

Fig. 2. Schemes of measuring deformation of the pipe.

$\mathrm{a}$ - the length of the chord; $\mathrm{h}$ - the height of the deflection; $\eta$ - change in radius.

After 10 minutes, the load on the sample was stopped, it was taken from mechanism (Figure 3) and trough height measurements in relation to the chord were carried out (Figure 4). Further samples of pipes were kept for one day in vivo. 24 hours later the measurements of diameters and the height of bending in relation to the chord were carried out again in order to evaluate elastic properties of the pipeline over time.

The value of the height of depression and its changes over time, do not by themselves make it possible to evaluate the elastic properties and, in what range (acceptable or unacceptable) is made pipe bend. The criterion for estimation can be stated by a requirement: the ratio between the diameter of the pipe and diameter of the bay, on which the pipe is wound, should not be more than $5 \%$ (d pipe / D bay $\leq 5 \%$ ). The height of deflection was estimated from this point. It can be argued that the pipe will not change physical and mechanical characteristics after application of bending load, if the following conditions are met:

1. The ratio of pipe diameter to the diameter of its bending after load application not exceed $5 \%$;

2. The return of the deformable pipe diameter to the value of the original size is ensured.

During the test, pipe samples were pressed to a bracket with a known radius (Rcr, the center of the circle - O1). After removal of the load they straightened to a new circle (center of the circle - O2) with an unknown radius (R) and a central angle $(\psi)$.

The calculation task included the definition of $\mathrm{R}$ in terms of the measured deflection height ( $\mathrm{h}$ ), followed by assessment of the ratio of $\mathrm{d}$ pipe / $\mathrm{D}$ bending and conclusions about the elastic properties and the level of deformation of pipes [13, 14, 19]. Fig. 3 


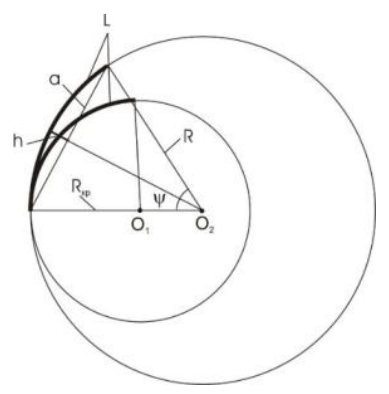

Fig. 3. Scheme to the determination of the bending radius of pipe samples at unloading.

The radius of the pipes samples after removal of the load can be determined from the ratio:

$$
R=h+R \cdot \cos \psi / 2
$$

Central angle $\psi$ after straightening of pipes samples can be determined, if the arc length of the bended part of sample pipes, which before and after the application of the bending force does not change and is calculated from equation:

$$
L=R_{b r} \cdot \frac{\pi}{2}=\psi \cdot R
$$

From (1), taking into account (2) we can obtain:

$$
\psi=\frac{\pi R_{b r}}{2 h}\left(1-\cos \frac{\psi}{2}\right)
$$

or

$$
\frac{\pi R_{b r}}{2 h}\left(1-\cos \frac{\psi}{2}\right)-\psi=0
$$

After the calculation of angle $\psi$ at removal of the load from the sample pipes, one can determine the radius of their bending $\mathrm{R}$ from relation $R=\frac{L}{\psi}$. The solution of the nonlinear transcendental equation (4) reduces to finding the value of $\psi$, in which the condition $\mathrm{f}(\psi)=$ 0 is satisfied. In a general view, a function $f(\psi)$ has no analytical formulas for finding the roots. Therefore, in this case, one of the iterative methods for solving nonlinear equations "bisection method" - is used. To find the root of the equation $\mathrm{f}(\psi)=0$, change interval of angle $\psi$ was divided in halves $\left[\frac{\pi}{180}, \frac{\pi}{90}\right]$, i.e. the initial approximation equal $\psi_{0}=\left(\frac{\pi}{180}+\frac{\pi}{90}\right) / 2$ was chosen. If a $(\psi)=0$, than $\psi 0$ is the root of the equation. 
Otherwise that of the segments $\left[\frac{\pi}{180}, \psi_{0}\right]$ or $\left[\psi_{0}, \frac{\pi}{90}\right]$ was chosen, for which the value of the function $f(\psi)$ have opposite signs at interval ends. This interval was divided in halves again, and selects that half, at the ends of which the function has opposite signs, etc. As a result, the calculation accuracy increased with each iteration $[5,7,8,9]$.

To substantiate the reliability of analytical calculations of stress states in the developed mathematical model, it was necessary to compare them to the results of experimental studies. For this purpose, the dynamic tests were carried out with sample pipes of different diameters. During the experiment, the samples were stretched with a walking traverse along the brackets with different radii. Measured efforts also allowed to estimate indirectly the voltages arising in a pipe, which then were calculated by the equation:

$$
\sigma_{s}=\frac{M z}{K J}\left[1-\beta\left(\frac{z}{r}\right)^{2}\right]
$$

where $\mathrm{M}$ - the bending moment; $\mathrm{z}$ - coordinate of the height of the pipe cross section ($\mathrm{dn} / 2<\mathrm{z}<\mathrm{dh} / 2$ ); J - axial moment of inertia; $\beta$ - flattening ratio; $\mathrm{K}$ - reduction ratio sectional of rigidity $[16,18,20]$.

Coefficient of reducing the cross section of rigidity $(\mathrm{K})$ takes into account the effect of flattening the thin-walled section in bending on relation between the bending moment and the change in curvature and is defined by from the equation:

$$
K=\frac{1+12 \lambda^{2}}{10+12 \lambda^{2}}
$$

where $\lambda$-geometric pipe coefficient.

Coefficient of flattening $(\beta)$ considers the fact that the coordinate $(z)$ on height of the cross section pipe required to calculate voltage value at flattening, changes its value regarding the neutral axis and is defined by the ratio:

$$
\beta=\frac{6}{5+6 \lambda^{2}}
$$

In its turn, pipe geometry coefficient $(\lambda)$ is calculated by formula:

$$
\lambda=\frac{\delta R}{r^{2}}
$$
$[6,7]$.

where $\mathrm{R}$ - radius of curvature of the bracket; $\mathrm{r}$ - the outer radius of the test pipe sample

During the experimental studies, the amount of force required to forced delivery of polyethylene pipe with a different diameter $[5,7,8,9]$ was determined. The magnitude of this effort allows determining the magnitude of the bending moment: 


$$
M=N_{S}\left(R+\frac{d}{2}\right)+Q\left(R+\frac{d}{2}\right)=N\left(R+\frac{d}{2}\right) \cdot(\cos \varphi+\sin \varphi)
$$

The measurement results were processed using statistical methods. All parameters were determined: the arithmetic average value of the measured parameter, individual measurement error, root mean square deviation [12,17] (Fig. 4).

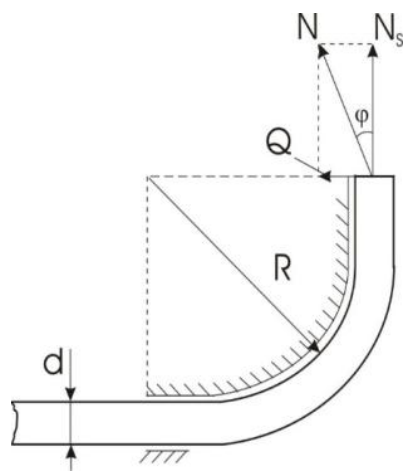

Fig. 4. The scheme to determine bending moment

It is known that the deformation experienced by a pipe in bending should take place within the elastic zone. Analysis of such changes is made on the basis of changes in pipe sample diameters, and their deflection values, and is presented in Table $1[7,8]$.

Table 1. The comparative fetch of results of experimental studies

\begin{tabular}{lccccc}
\hline \multicolumn{2}{c}{$\mathrm{R}=80[\mathrm{~mm}]$} & \multicolumn{2}{c}{$\mathrm{R}=157.5[\mathrm{~mm}]$} & \multicolumn{2}{c}{$\mathrm{R}=315[\mathrm{~mm}]$} \\
\hline $\mathrm{t}=0$ & $\begin{array}{l}\mathrm{t}=24 \\
\text { hours }\end{array}$ & $\mathrm{t}=0$ & $\begin{array}{l}\mathrm{t}=24 \\
\text { hours }\end{array}$ & $\mathrm{t}=0$ & $\begin{array}{r}\mathrm{t}=24 \\
\text { hours }\end{array}$ \\
$\mathrm{d}=16 \mathrm{~mm}$ & 15.91 & $16.15 \pm 0.11$ & 16.08 & $16.14 \pm 0,10$ & 16.06 \\
$\begin{array}{l}16.13 \pm 0,11 \\
\mathrm{~d}=25 \mathrm{~mm}\end{array}$ & & & & & \\
$25.07 \pm 0,09$ & 24.51 & $25.15 \pm 0.16$ & 25.04 & $25.14 \pm 0,08$ & 25.07 \\
$\mathrm{~d}=32 \mathrm{~mm}$ & & & & & \\
$32.19 \pm 0.09$ & 28.81 & $32.17 \pm 0.10$ & 31.99 & $32.15 \pm 0,10$ & 32.10 \\
$\mathrm{~d}=40 \mathrm{~mm}$ & & & & & \\
$40.18 \pm 0,07$ & 37.17 & $40.16 \pm 0.14$ & 39.94 & $40.20 \pm 0,09$ & 40.13 \\
\hline
\end{tabular}

\section{Conclusion}

After the experiment, the following conclusions can be made:

1. 24 hours after the removal of bending stress by using the bracket with radius of 315 $\mathrm{mm}$, the average value of the diameters of all pipes samples is in the area of confidence ranges of measurements before load applications.

2. At the bracket radius with a radius of $157.5 \mathrm{~mm}$, the same ranges are characterized only by samples with diameters of 16 and $25 \mathrm{~mm}$. For pipes with diameters of 32 and $40 \mathrm{~mm}$ one day after the bending removal the load dimensions are not restored.

3. When using the bracket with a radius of $80 \mathrm{~mm}$, for all pipes samples, diameters complete return to its original dimensions does not occur. 
Change of pipe samples along the height deflection is shown in Figure 5.

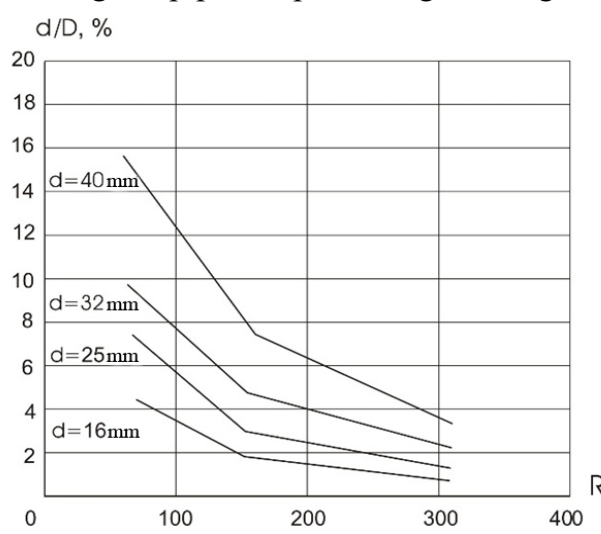

a)

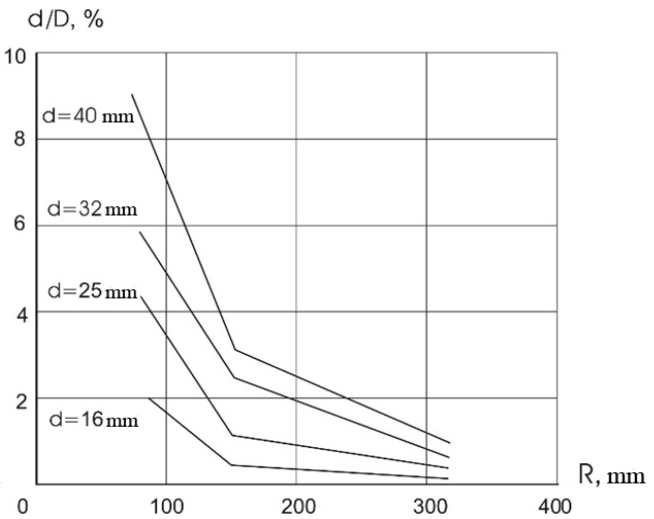

b)

Fig. 5. The ratio of the diameter of the pipe samples to bend diameter. a) after unloading, b) 24 hours after unloading

Taking into account that the indirect confirmation of the maintenance of physical and mechanical properties of the pipe is the return of its diameter to its original size and the ratio of pipe diameter to bend diameter of not more than $5 \%$, it could be argued that the use of the radii of less than $80 \mathrm{~mm}$ is impossible.

Also, it can be argued that at bending of pipes of studied diameters, on the bracket with a radius of $157.5 \mathrm{~mm}$, in the elastic area, only pipes with diameters of $16 \mathrm{~mm}$ and $25 \mathrm{~mm}$ work.

Thus, the results presented in the paper can be used for engineering calculations of mechanisms used in trenchless pipeline repairing with use of polyethylene inserts.

\section{References}

1. V. Ivanov, V. Kochurova, D. Serebrennikov, A device for trenchless laying of polyethylene pipelines. A patent for an invention RUS 2237783, 2003.

2. I. Lavrov, D. Serebrennikov, Problems of transport systems functioning: Proceedings of All-Russian scientific-practical conference, 247-251 (2012)

3. I. Lavrov, D. Serebrennikov, Problems of operation of transport systems: Proceedings of All-Russian scientific-practical conference, 178-181 (2008)

4. I. Lavrov, D. Serebrennikov, Land transport and technological systems and tools: Proceedings of International scientific-technical conference, 177-181 (2015)

5. D. Serebrennikov, I. Lavrov, Z. Khakimov, Problems of transport systems functioning: Proceedings of All-Russian scientific-practical conference of students, graduate students and young scientists, 344-348 (2012)

6. D. Serebrennikov, I. Lavrov, Materials of International scientific-technical conference, 130-134 (2005)

7. D. Serebrennikov, Justification of machine operating parameters for trenchless laying of polyethylene pipelines, thesis of candidate of technical sciences (TSOGU, Tyumen, 2004)

8. D. Serebrennikov, Justification of machine operating parameters for trenchless laying of polyethylene pipelines, abstract of thesis of candidate of technical sciences (TSOGU, Tyumen, 2004)

9. Yu. Zemenkov, V. Shalay, M. Zemenkova, Procedia Engineering, 113, 254-258 (2015) 
10. V. Kurushina, Yu. Zemenkov, WIT Transactions on Ecology and the Environment, 190(2), 881-888 (2014)

11. E. Kurushina, V. Life Science Journal, 11(11), 517-521 (2014)

12. A. Serebrennikov, S. Kurochkin, Operation and service of transport technological machines: Proceedings of the conference, 174-176 (2003)

13. A. Serebrennikov, I. Lavrov, Oil and Gas, 7, 42-45 (2007)

14. A. Serebrennikov, Z. Khakimov, Scientific and technical bulletin of the Volga region, 6, 382-386 (2012)

15. K. Voronin, Yu. Zemenkov, Oil and Gas, 3, 70-72 (2012)

16. A. Serebrennikov, I. Lavrov, D. Serebrennikov, Proceedings of the $X$ international conference on permafrostology, 467-469 (2012)

17. A. Serebrennikov, I. Lavrov, Z. Khakimov, Science, Equipment, Innovations: Proceedings of the international scientific and technical conference, 68-72 (2014)

18. A. Serebrennikov, I. Lavrov, V. Konev, Engineering bulletin of Don, 4, 3271 (2015)

19. D. Serebrennikov, A. Davydov, Innovations in modern science: Proceedings of VIII International spring symposium, 130-135 (2015)

20. D. Serebrennikov, S. Yakubovskaya, Yu. Sysoyev, M. Chekardovsky, Modern problems of science and education, 2-3, 45 (2015)

21. V. Vijayan, H. Bae, T. Marti, S. Choi, Polymer Testing, 53, 338-346 (2016)

22. N. Sun, M. Wenzel, A. Adams, Polymer, 55(16), 3792-3800 (2015)

23. L.E. Pimentel Real, Polymer Testing, 49, 88-93 (2016)

24. A. Leuteritz, K.-D. Döring, T. Lampke, I. Kuehnert, Polymer Testing, 51, 142-147 (2016) 